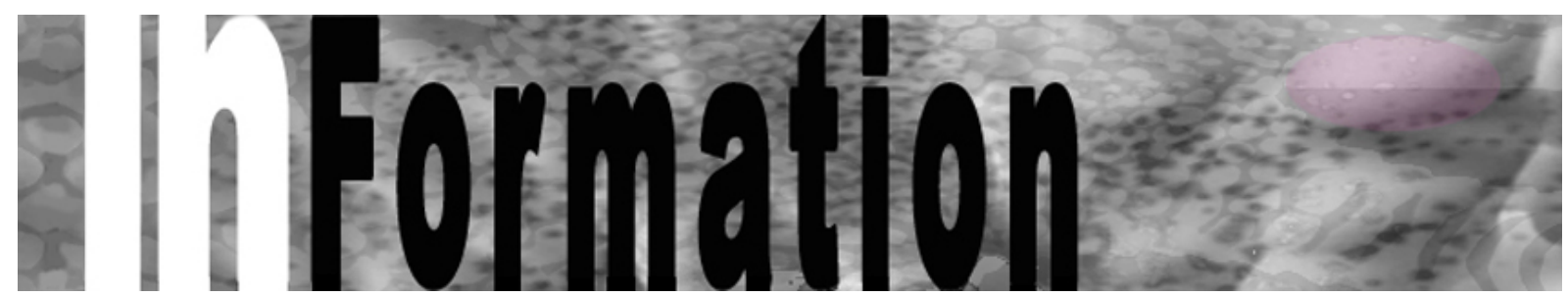

Nordic Journal of Art and Research

ISSN: 1893-2479

www.artandresearch.info

\title{
"Det aller største mor vet om ...": Om å gi videre et levd liv med musikk og å formidle for lite
}

\author{
Ingeborg Lunde Vestad ${ }^{1}$ \\ Høgskolen i Hedmark
}

Sammendrag: Artikkelen dreier seg en mors inderlige ønske om å gi videre Prøysens barneviser til sin 5 -årige sønn. Hun kjenner visene godt fra egen oppvekst, og har gode barndomsminner knyttet til dem. Selv beskriver hun formidlingen som «mislykket», for sønnen er ikke interessert. I artikkelen utforskes årsakene til at formidlingen "går galt» ved å se nærmere på morens forhold til barnevisene i egen barndom, radioens formidling av visene som del av barnetimeprogrammene og cd-platen moren har valgt for å formidle barnevisene til sønnen. Artikkelen er bygget på kvalitativt forskningsintervju med mor og sønn og arkivforskning er benyttet for å belyse radiomediet. Cd-platen er analysert som helhet, i tillegg til at det er gjort grundigere analyser av utvalgte viser. Ved å sammenholde datamaterialet med teoretiske perspektiver på musikk i hverdagsliv og perspektiver på medier, søker artikkelen å utdype morens opplevelse av barnevisene i voksen alder. Meningstilskrivelsene hun gjør når hun lytter til barnevisene på den aktuelle cd-platen sammenliknes med sønnens meningstilskrivelser. På bakgrunn av dette foreslås et begrep om «for-lite-mediering» - hypomediering - for å beskrive en mediering som er «for trang» for det intenderte budskapet og som hindrer barnets opplevelse heller enn å gi den næring slik at den blomstrer.

Emneord: Musikalsk barnekultur, medier, Alf Prøysen, barnetimen, hypomediering.

\section{Innledning}

Det aller største mor vet om, er nemlig guttemann, som kommer hjem og har med seg sin første løvetann. Slik lyder de to siste strofene av Alf Prøysens vise Den første løvetann. Visen kan leses som en hyllest til en mors kjærlighet til sitt barn. I denne kjærligheten reforhandles oppfatningen av

\footnotetext{
${ }^{1}$ Høgskolen i Hedmark, Avdeling for lærerutdanning og naturvitenskap, Postboks 400, 2418 Elverum. E-post: Ingeborg.Vestad@hihm.no.
} 
løvetannens estetiske kvaliteter: Den pjuskete blomsten blir vakker når den får status som sønnens første.

I denne artikkelen utforskes en mors formidling av musikk til sin 5-årige sønn. Det er ikke tilfeldig at artikkelen innledes nettopp med teksten fra en Prøysenvise. Moren har nemlig gode barndomsminner knyttet til Prøysens barneviser, og beskriver dem som «god musikk» og som å være noe «ekte». Hun har et inderlig ønske om å gi disse visene videre til sønnen ved å høre på innspillinger av dem og synge dem sammen med ham. Selv beskriver hun imidlertid formidlingen som «mislykket», for sønnen virker over hodet ikke interessert. Han vil heller høre på det samme som vennene hører på, forklarer hun. Prøysens vise om den første løvetann tjener som et bilde på hvordan moren, i møte med sønnens opplevelse av musikk, til sist reforhandler sin forståelse av musikalsk kvalitet.

Artikkelen fokuserer på det moren beskriver som «mislykket» formidling av Prøysens barneviser, med mål om en utvidet forståelse av hva moren ønsker å formidle til sønnen og hvorfor det ikke fungerer slik hun ønsker. Hvilke medier som stilles til rådighet for formidlingen og hva de tilbyr, kobles til musikkopplevelse og levd liv. «Medium» er latin for «i midten» eller «midterst» og anvendes for å beskrive det som ligger «imellom». All kommunikasjon forutsetter et medium. I artikkelen foreslås begrepet hypomediering - «for-lite-i-midten» - for å beskrive det som skjer når noe formidles «for lite». Konseptet innebærer at den som formidler har mer på hjertet enn det som kan rommes av mediet eller mediene som tilbys. Medieringen er dermed utilstrekkelig i kvalitet og omfang, og den det formidles til berøres ikke, gripes ikke og opplever distanse i stedet for nærhet.

\section{Teoretiske tilnærminger og begreper}

\section{Cultural studies}

Tidligere forskning innenfor sosiologi viser nettopp at foreldre, som moren i det aktuelle eksempelet, bruker sine egne barndomserfaringer som inspirasjon når de formidler kulturskatter til neste generasjon (Wetlesen, 2000). I denne artikkelen anvendes en cultural studies-orientert tilnærming for å utdype hvordan moren bruker en cd-innspilling til å formidle musikk til sønnen. Det finnes relativt lite forskning på barnekultur $\mathrm{i}$ et cultural studies-orientert medieperspektiv, sammenliknet med mengden forskning som finnes på ungdomskultur (Buckingham, 2008). Likevel er tilnærmingens vektlegging av det multi-dimensjonale og premisset om kultur som sosial prosess interessante for en analyse av morens formidling og sønnens, i hennes øyne, manglende opplevelse.

Basert på egen erfaring presenterer Buckingham (2008) en modell bestående av tre dimensjoner; produksjon, tekst og publikum. Produksjon dreier seg om de øyeblikkene der kulturell tekst skapes. Teksten antar spesifikke former og kan analyseres med disse for øyet. Tekstenes mening aktualiseres i øyeblikket de leses av mennesker og har sterk tilknytning til levd liv. Sosiale forutsetninger og relasjoner påvirker hvert punkt i modellen, og analysene kan dermed bli svært komplekse. Jeg har latt meg inspirere av Buckinghams modell og definerer her tre dimensjoner som gjøres til gjenstand for analyse, for å utvide forståelsen av mor og sønns respektive tilskrivelser av mening til barnevisene. Disse tre er morens barndomsminner, barnevisene i radioen og den aktuelle cd-platen.

Intervjuet med mor og sønn danner artikkelens empiriske kjerne. Sentrale sider ved deltakernes musikkopplevelse støttes av historiske data om radio og kringkasting, med vekt på tankene bak og innholdet i Barnetimen for de minste og Barnetimen. Dette materialet er en del av et pågående forskningsprosjekt om barnemusikkens historie i Norge, og er fremskaffet gjennom arkivstudier og intervjuer med nøkkelpersoner. For å forstå formidlingshendelsens partikularitet trekkes cd-platen inn 
som artikkelens tredje og siste gjenstand for analyse. Denne analysen er gjort spesifikt for denne artikkelen, og fokuserer på både cd-platens innhold og cd-platen som en remediering av radiomediet.

\section{Music in everyday life}

For å følge opp premisset om at meningsskaping er tett knyttet til levd liv (Buckingham, 2008), støtter artikkelen seg til forskning på musikk i hverdagsliv (music in everyday life). Med DeNora (2000) kan en si at musikkens mening og betydning skapes i en bestemt situasjon hvor en bestemt lytter hører på bestemt musikk. Dette gir rom for at mor og sønns meningstilskrivelser kan være svært ulike, og det partikulære ved musikkopplevelse framheves som interessant.

Innenfor forskning på musikk i hverdagsliv fremheves også betydningen av minner og minnearbeid (Ruud, 1997). Minner og minnearbeid framstår som sentrale ressurser for morens meningstilskrivelser. Dette utdypes når selve eksempelet er presentert.

\section{Remediering, immedialitet og hypermediering}

For å utdype hvordan mediene radio og cd samspiller i det aktuelle eksempelet, introduseres begrepene remediering, hypermediering og immedialitet (Bolter \& Grusin, 1999). Remediering beskriver en forflytning fra et medium til et annet, og innebærer i vår sammenheng at cd-platen tar opp i seg noe av radiomediet samtidig som det nye mediet (cd-en) tilfører noe nytt. Radiomediet «henger med» (jf. Bolter \& Grusin, 1999) når moren hører barnevisene på cd. Sentrale prinsipper i forbindelse med remediering er immedialitet og hypermedialitet. Immedialitet beskriver umiddelbarhet og direkte opplevelse, settes i sammenheng med autentisitet og «nærvær», og har som mål at mediet glemmes. Hypermedialitet beskriver en overflod av medier, som (paradoksalt nok) også strever mot å glemme mediet. Prinsippene forsøker altså på hver sin måte å «viske ut» mediene, og de forstås som motsetninger, som allikevel virker sammen. Bolter og Grusins teori handler om teknologisk utvikling og om selve mediet, og det opplevelsesmessige aspektet skyves noe i bakgrunnen, sammenliknet med de mer antropologiske tilnærmingene som gjør seg gjeldende i forskning på musikk i hverdagsliv.

\section{Hypomediering}

Sammenstillingen av mer antropologisk orienterte perspektiver på menneskers hverdagslige musikkopplevelser og perspektiver som sier noe mer om selve mediene, resulterer $\mathrm{i}$ en multidimensjonal analyse. Denne analytiske tilnærmingen bidrar både til å synliggjøre fylden og rikdommen i morens opplevelse, og til å utdype forståelsen av sønnens manglende opplevelse av meningsfylde.

For å beskrive formidlingen i dette eksempelet oppstår et behov for et begrep som kan romme det at en ønsket musikkopplevelse ikke når fram. Det som skjer i eksempelet kan beskrives som «for-litemediering», «under-mediering» eller hypomediering. I artikkelen foreslås begrepene hypomediering og distanse, som spiller på Bolter og Grusins (1999) begreper om hypermediering og immedialitet, for å beskrive mediering som er utilstrekkelig. Opplevelsen kveles, som i mangel på surstoff. Den det formidles til berøres ikke og gripes ikke, og opplever distanse i stedet for nærhet. Den kvalitative og kvantitative utilstrekkeligheten i medieringen bidrar til å gjøre selve mediet synlig, heller enn å overskride det. Denne synliggjøringen av mediet hindrer opplevelse karakterisert som «nærvær». «Medium» er som nevnt latin for midten eller midterst og anvendes for å beskrive det som ligger «imellom», og all kommunikasjon forutsetter et medium. I dette eksempelet kan barnevisene beskrives som et medium som er ment å formidle morens barndomsverden til sønnen. En bruk av begrepet «medium» som er mer i tråd med Bolter og Grusins teori innebærer å fokusere på cd-en/cd-spilleren 
og radioen. Begge disse to forståelsene legges til grunn for analysen, og i begge tilfeller er morens budskap for stort for det hun tilbyr «i midten». ${ }^{2}$

\section{Å høre på Prøysens barneviser på cd - et eksempel fra empirien}

Eksempelet som er denne artikkelens utgangspunkt er hentet fra et større materiale fremskaffet gjennom observasjon og kvalitative intervjuer av barn, barnehageansatte og foreldre om barnas bruk av fonogrammer (cd, mp3-filer osv.) i hverdagssammenhenger (Vestad, 2004; 2013). Eksempelet er rikt på informasjon og viktig for de involverte. Intervjuet skiller seg fra de øvrige ved at moren spesielt nært og ærlig berører en sorg som nevnes i enkelte intervjuer, og fornemmes i flere, men som sjelden utdypes. I dette intervjuet forsøkte moren å sette ord på hvordan hun forsøker å skape en god barndom for sønnen gjennom musikk og hva sorgen består i når sønnen ikke vil høre på den musikken som hun så gjerne vil gi ham. I denne sammenhengen er det nok mer tilfeldig at det er Prøysens barneviser eksempelet dreier seg om. Datamaterialet inneholder mange eksempler på at barn knytter seg tett til Prøysens viser også i dag.

Eksempelet presenteres her som en kombinasjon av intervjusammendrag i narrativ form (Kvale \& Brinkman, 2009) og et feltnotat som utdyper tid, sted, situasjon og følelser som kom til uttrykk (Hammersley \& Atkinson, 2007). Begynnende analyser som ble skrevet ned rett i etterkant av intervjuet er tatt med i feltnotatet:

Jeg er invitert til å ta plass i sofakroken hjemme hos familien. Sønnen sitter ved sofabordet og tegner, og moren finner fram te og kjeks. Stemningen er god, men samtidig litt spent. Det løser seg snart opp, og vi snakker lenge om musikkbruken i familien. Sønnen viser meg cd-spilleren og en del cd-er, som han beskriver som «alle cd-ene». Han forteller meg om hvilke han liker best og hvorfor. Noen cd-er hører de på sammen, noen er mest morens og noen er mest sønnens. Etter en stund begynner moren uoppfordret å fortelle om de cd-ene som ikke er der, de som sønnen ikke har funnet fram. Blant dem er det én som hun gjerne skulle ønske at sønnen og hun kunne høre på sammen, men som han ikke liker. Dette er en cd med Prøysens barneviser fra serien Original Prøysen, forklarer hun. (Cd-ens fulle tittel er Original Prøysen 4: Hompetitten, 42 barneviser (1946 - 57), Prøysen 1993a). Det er en inderlighet, sårhet og tristhet i morens stemme på dette punktet i samtalen, og stemningen i intervjuet skifter. Moren husker visene på denne cd-en godt fra egen barndom. Da framførte Prøysen sangene i radioen, og hun lyttet til dem i Barnetimen for de minste og i Lørdagsbarnetimen. Dette var musikk og sanger som alle kunne da hun var barn, vektlegger hun. Det hendte at hele familien samlet seg rundt radioapparatet. Hun beskriver varmen, nærheten og felleskapet mellom familiemedlemmene og den gode, trygge følelsen hun hadde. Øynene hennes fylles av tårer og det er tydelig at hun er rørt når hun forteller om disse minnene. Hennes gjenopplevelse av visene i voksen alder framstår som svært betydningsfull.

Som mor har hun et sterkt ønske om å la sønnen kjenne tilsvarende følelser av trygghet, nærhet og kjærlighet gjennom barnevisene som hun forbinder med å lytte til visene sammen med søsken og foreldre. Men sønnen er ikke interessert. Han er mye mer interessert i det hans jevnaldrende hører på. At de ikke kan glede seg over barnevisene sammen, beskriver hun som «leit» og som «en stor sorg». Hun utdyper ved å forklare at det at sønnen ikke er interessert i visene, fører til at hun føler seg ensom og at han ikke får den gode musikkopplevelsen.

\footnotetext{
${ }^{2}$ «Nærvær» framstår her som et ideal, men er ikke nødvendigvis det i Bolter og Grusins (1999) teori. I morens fortelling er imidlertid nærværet og direkte opplevelse sentralt.
} 
Når det gjelder valget av denne bestemte cd-platen forteller hun at hun generelt lette lenge for å finne musikk til sønnen som hun syns var god. Hun valgte den nevnte cd-en bevisst, fordi Prøysen selv synger på den. Akkurat det var svært viktig for henne. Hun beskriver Prøysens barneviser framført av Prøysen selv som «god musikk» og noe «ekte», og nettopp dét ønsker hun å formidle til sønnen. Hun er ikke så glad i sånn type musikk som «kuer med fletter og jura på snei», med henvisning til en cd-utgivelse med Trond Viggo Torgersen. Hun er ute etter det nære og varme, det med kvalitet, som handler om «noe ordentlig» og som har gode fortellinger i sangene og rundt sangene, som barn og voksne kan samles om. Det er heller ikke så aktuelt å skaffe innspillinger av Prøysens barneviser med andre artister, sier hun. Det blir ikke det samme. Hun framhever fortellingene om de fem barna Pelle, Kari, Mari, Kjell og Lillebror, og nevner på nytt nærheten, tryggheten og fellesskapet mellom familiemedlemmene rundt radioen. Det er som om Prøysens stemme bærer i seg hele hennes barndomsverden.

Moren uttaler at det er viktig for henne å gi sønnen en «trygg forankring» og «god ballast» $\mathrm{i}$ livet i form av musikk, siden hun selv har opplevd at musikk gir så mye glede. På dette punktet beskriver hun musikk som «en gave».

Hun er greit fornøyd med cd-valget, forklarer hun. Det er noe som er annerledes enn hun husker det, men hun er ikke sikker på hva. Hun spør seg om det kan være måten Prøysen synger på eller noe ved klangen i stemmen. Hun mener dette kan være noe av grunnen til at sønnen ikke liker visene, men hun foreslår også at han reagerer på den susete lyden på opptaket. På dette punktet i intervjuet nikker sønnen, som under denne delen av intervjuet har virket utilpass og litt trist. Han ville ikke si noe særlig om denne cd-en, men beskrev både cden og musikken som «mammas musikk», «gammeldags» og «kjedelig». Han syns mannen som synger er «rar» og synger «rart», utdyper han.

\section{Morens erfaring i lys av minner og minnearbeid}

Morens ønske om å gi Prøysens barneviser videre til sønnen er inspirert av opplevelser i egen barndom og hennes opplevelse av visene i nåtid er preget av minner om hennes barndomsopplevelser og minnearbeidet hun gjør. At musikk virker som en døråpner for minner er velkjent innenfor antropologisk og sosiologisk teori. Even Ruud (1997) skriver at å lytte til musikk en forbinder med tidligere faser i livet kan få minnene til å strømme på, og at minnene knyttes til en bestemt tid og sted. Han utdyper det slik: «Tid og sted er uløselig knyttet til hverandre, også i musikkopplevelsen. Når jeg lar musikken utløse minner, knyttes disse an til et 'den gang og der' - når og hvor jeg opplevde musikken» (ibid., s. 145). Et «sted» består i antropologisk forstand av tiden (tidsånden), historien og kulturbærende mennesker som bidrar til og opprettholder stedet (Casey, 1996, s. 44). Minnene våre inneholder ofte en slik helhet, noe morens fortelling er et eksempel på.

Tia DeNora (2000) er på linje med Ruud når det gjelder musikkens muligheter til å vekke minner. Verken DeNora eller Ruud beskriver avspillingsmediet i særlig grad, men DeNora legger til en metafor om musikk som beholder [container] som er fruktbar i forbindelse med analysen av medienes betydning for opplevelse av Prøysens barneviser. Metaforen gir mulighet til å kunne beskrive at når en lytter til musikk lagres minner om tiden og stedet i antropologisk forstand nærmest som $i$ musikken. Når en etter en periode slutter å høre på den spesifikke musikken er det som å skru lokket på beholderen. Senere i livet, når en tilfeldig eller bevisst lytter til den samme musikken på nytt, kan det i mange tilfeller sammenliknes med å åpne lokket på beholderen, og minnene om tid og sted strømmer ut. En kan oppleve minnene svært livaktig, som om en virkelig kjenner sin barndoms lukt og føler menneskenes tilstedeværelse. Cd-platen kan forstås som et skap for flere slike beholdere. Ved å sette cd-en i cd-spilleren åpnes skapet og cd-spilleren fungerer videre som en «boksåpner» for hver enkelt beholder etter tur. 
Beholdermetaforen bidrar til å forklare noe av forskjellen mellom morens og sønnens opplevelse av musikken. For moren er opplevelsen resultat av et minnearbeid hvor barndommens erfaringer og selve minnene om dem tilskrives mening i nåtid (jf. Ruud, 1997). Sønnen har ikke erfaring med visene fra tidligere, og for ham er det ingen tilsvarende beholder som åpnes, som gjør at en hel barndoms verden oppleves å «strømme ut».

\section{Morens erfaring i lys av Proysens barneviser spilt i radio}

Før en analyse av den aktuelle cd-en og dens innhold, vil jeg i det følgende se nærmere på barnevisene framført i radiomediet og knytte dette til morens minner. Sentrale momenter er NRK som allmenkringkaster og radioen forstått som et medium for nærhet, men først vil jeg si litt om barnetimeprogrammene som kontekst for morens (gjen)opplevelse av barnevisene.

Den aller første barnetimen i norsk radio ble sendt den 20. desember 1924, som «eventyrtime» med opplesning og barnesanger (Dahl, 1999, s. 88). Barnetimen som programpost utviklet seg på 1930-tallet og etter andre verdenskrig fortsatte programmet som et lørdagsprogram (Lørdagsbarnetimen). Når det gjelder Barnetimen for de minste ble det sendt tre programmer før sommeren i 1947. Fra og med 5. oktober samme år ble programmet sendt regelmessig på mandag ettermiddager klokken 17.05 (Programbladet, 1947). ${ }^{3}$ Fra 1952 og framover ble Barnetimen for de minste sendt hver ukedag (Ditlefsen, u. å). Utover årtiene har programmet endret sendetid og form flere ganger, fram til det siste programmet ble sendt i 2013 (Bergmo, 2013).

Barnetimen for de minste var i etterkrigstiden inspirert av et australsk barneprogram, og en av de primære intensjonene med programmet var å gi et pedagogisk tilbud til barn som ikke gikk i barnehage (Ditlefsen, 1995). Selv om programmene kanskje er mest kjent for opplesninger av fortellinger og hørespill, sto også sang og musikk sentralt. Else Wennevik (senere Wildhagen) sine barnetimer var bygget opp som en musikkstund, på liknende vis som samlingsstunder med musikk i barnehagen. Det ble spilt piano i studio og Wennevik henvendte seg til barna hjemme foran radioapparatet, for å engasjere dem. Ifølge NRKs arkiver fant Prøysens første opptreden i Barnetimen sted 17. august 1946. Visene han framførte var Blåbærvisa, Sirkusvisa og Godnattsang (Kongsrud \& Kristiansen, 2014). Utover på 1950-tallet ble det som nå framstår som den tradisjonelle formen på Barnetimen for de minste etablert, bestående av en kombinasjon av fortellinger og viser, sanger eller annen musikk. Både Alf Prøysen, Thorbjørn Egner og Anne Cath. Vestly bidro sterkt til utviklingen av denne formen.

En gjennomgang av referater fra Programutvalgets møter i årene 1945 til 1959 viser at forståelsen av NRKs rolle som allmennkringkaster sto sentralt i utvalgets arbeid. En var for eksempel oppmerksom på at alle lyttere skulle tilgodeses med relevant innhold i programmene, enten de bodde på den ene eller andre kanten av landet, på landet eller i byen. Det var derfor viktig at de som formidlet i barnetimen kom fra ulike steder og hadde ulike dialekter, som speilet mangfoldet i Norge. Prøysen var en stemme fra distriktet. Den slentrende fortellerstilen var et av hans særpreg. Hans barnetimer gir dessuten assosiasjoner til stammens eldste som forteller ved leirbålet (Bjarne Grevsgard, personlig kommunikasjon, 6. mars 2015). Denne nære fortellerstilen var nok noe av årsaken til hans store popularitet.

\footnotetext{
${ }^{3}$ Informasjonen er basert på forfatterens gjennomgang av NRKs Programbladet fra de første utgavene etter siste verdenskrig og fram til 1948.
} 
$\AA$ henvende seg direkte til barna hjemme ved radioapparatet var som jeg var inne på vanlig allerede i Wenneviks barnetimer. Et annet eksempel finnes i et av Amund Schröders manus fra 1958 som begynner slik:

Morn! Morn! Er du på plass foran radioen? Det var kjekt. Og her inne i radioen sitter j e g. Sa $\mathrm{d} u$ morn til m e g? Tenk, jeg hørte visst ikke riktig, jeg. Kan du si det en gang til? Tror du? Får jeg høre - - Ja visst ja, n å hørte jeg det! (Schröder, 1958).

De som nok huskes aller best for slik toveis kommunikasjon med barnetimeprogrammenes lyttere er Prøysen, Egner og Vestly. Prøysen er særlig kjent for sin oppfordring om at «nå legg du handa på radioen din, så legg je handa på radioen min»». ${ }^{4}$ Det er som om moren i voksen alder legger hånda på cd-spilleren slik hun gjorde på radioen som barn, og som om denne berøringen gjengjeldes, ikke på den andre siden av eteren som i radioen i hennes barndom, men av henne selv som barn. Musikken gir en følelse av nærmest direkte kontakt mellom nåtiden og egen historie. Hun kommer i berøring med følelser av trygghet, glede og samhørighet med familiemedlemmene som samlet seg rundt radioapparatet. Det skaper en opplevelse av sammenheng i hennes liv, mellom rollene som noens barn og som noens mor. I dette henter hun bekreftelse på hva som er viktig for barn og inspirasjon til å utøve sin egen morsrolle.

Morens personlige erfaringer med Prøysens barneviser i barnetimeprogrammene smelter sammen med den offisielle fortellingen. Om hun er klar over dette, forteller ikke intervjuet noe om. For moren ble det uansett et sterkt møte med egen barndom og barndommens emosjonelle landskap da hun satte på cd-en med Prøysen-visene, og hennes fortelling i intervjuet bekreftes av den offisielle fortellingen om faktiske intensjoner med programmene; hun har på en måte opplevd det helt riktig, i betydningen akkurat slik kringkastingen ønsket at hun skulle oppleve det.

\section{Fra radioprogram til musikk-cd}

Med remedieringsbegrepet kan en beskrive cd-platens etteraping av radiomediet. Cd-mediet tilbyr noe nytt, samtidig som det gamle mediet (radioen) er tilstedeværende i det nye (cd-en). Allerede på omslaget av cd-en er det tydelig for en som har lyttet til Prøysens radiobarnetimer at cd-platen peker tilbake på barnevisenes tidligere framføringer nettopp i radioen. Serietittelen Prøysen original og årstallene «1946-1957» på omslagets forside bidrar til dette, sammen med sort-hvitt-fotografier av Prøysen selv, som tilbyr assosiasjoner i retning av at historisk autentisitet.

Bolter og Grusins (1999) teori om remediering handler som nevnt mest om selve mediet og i mindre grad om mennesket som opplever. Likevel er et av deres sentrale poenger at en forutsetning for et samspill mellom medier er at leseren eller seeren kjenner til de ulike medieversjonene: «The interplay happens, if at all, only for the reader or viewer who happens to know both versions and compare them», skriver de (Bolter \& Grusin, 1999, s. 45). Denne forutsetningen bidrar til å tydeliggjøre at for moren henger opplevelsen av radioen med når hun lytter til cd-en. Sønnen som er uten denne erfaringen av og med radiomediet får ikke tak i dette samspillet. Dette utdyper perspektivet om minner og minnearbeid som er presentert tidligere i teksten ved å legge til selve mediet som dimensjon i analysen.

Moren beskriver i intervjuet at en kvalitet ved Prøysens barneviser er det gode innholdet, forstått som de gode fortellingene som barn og voksne kan samle seg om. Hun forteller om barna Pelle, Kari, Mari, Kjell og Lillebror, og setter fortellingene i sangene i sammenheng med radioprogrammene. Selv

\footnotetext{
${ }^{4}$ Sitert fra et utklipp om Prøysens barnetimer, sannsynligvis fra Programbladet, med ukjent forfatter og uten årstall. Notatet er hentet fra NRKs Dokumentarkiv.
} 
om noe tekst og noen regler er tatt med på cd-en, framstår produksjonen i svært stor grad som en musikk-cd. Fortellingene som rammet inn visene er ikke med. Denne tilpasningen gjør at visene mister noe av sin potensielle meningsfylde, særlig for nye lyttere. Barnetimeprogrammene kan betraktes som et helhetlig verk, hvor fortelling og musikk understøtter og utdyper hverandre. Dersom en tar bort den ene dimensjonen, mister også den andre noe. Det er selvfølgelig ikke slik at barnevisene, eller fortellingene for den sakens skyld, ikke kan stå alene, men i denne analysen er mor og sønns ulike utgangspunkter for opplevelse av barnevisene på cd i fokus. At fortellingene er utelatt fra cd-en innebærer at hun har et forhold til hele verket, mens sønnen kun har mulighet til å forholde seg til visene og til fortellingene slik de formidles i visene.

\section{Radioen som allmenkringkaster vs. cd-en som privat medium}

Nok et bidrag til å stille sønnen utenfor morens definisjon av visenes betydningsinnhold knytter seg til forskjellen mellom radioen som allmennkringkaster og cd-platen som et mer privat medium. Moren formidler en klar oppfatning av at alle kunne disse visene i hennes barndom, for alle hørte på radioen. En åpenbar fordel med cd-mediet er at lyttere gis mulighet til å lytte til musikk når de selv ønsker det. En konsekvens av cd-ens mulighet for publikums løsrivelse fra bestemte sendeskjemaer og klokkeslett er på den andre siden at mens radioen skapte følelse av felleskap mellom familiemedlemmer, barn i andre familier og andre voksne i morens barndom - altså en felles identitet som hun nå gjenopplever og re-konstituerer i minnet - er sønnen klar over at det kun er han i vennegjengen som hører på Prøysens barneviser. I stedet for å bekrefte en plass i felleskapet, bidrar denne musikken til å gjøre ham annerledes, på en måte som han ikke finner positiv og tilfredsstillende. Mens moren opplever fellesskap gjennom visene, uttrykker sønnen i intervjuet seg i retning av utilpasshet og ensomhet.

\section{Proysen som barnetimeonkel - betinget av radiomediet?}

Prøysen var som tidligere beskrevet kjent for sin nære og varme fortellerstil. Inspirert av Bolter og Grusins (1999) beskrivelser av det gamle mediet som til stede i det nye, viser eksempelet at opplevelsen av Prøysens kommunikasjon med radiopublikummet «henger med» når moren lytter på cd-en. Den lette og ledige formidlerstilen Prøysen etter hvert ble så kjent for er mindre synlig på cd-en i seg selv, og formidlingen her framstår samlet sett som stivere. Som jeg beskrev ovenfor innebærer vektleggingen av visene en reduksjon sammenliknet med opplevelsen av visene som en del av barnetimeprogrammene. Prøysens samspill med lytteren er også en viktig del av barnetimeprogrammene. Barna i morens barndom ble trukket inn i hans nærhet gjennom at han ba dem om å legge hånda på radioen sin, mens han la hånda si på radioen fra den andre siden, forteller hun. Dette innebar i seg selv et ønske om overskridelse av mediet, mot en opplevelse av umiddelbarhet. Det skapte en illusjon av at Prøysen faktisk befant seg fysisk i et studio på Marienlyst og snakket direkte med barna, selv når programmene var opptak eller ble sendt i reprise. Dette var nok kanskje enklere å oppnå på 50- og 60-tallet enn i dag. Sønnen i dette eksempelet er i alle fall svært klar over at det ikke er en ekte person inne i verken cd-spilleren eller cd-platen.

\section{Proysens sangstemme - distanse eller noerhet?}

Sønnen legger merke til «suset» på denne cd-en, som skiller seg fra de andre cd-ene han viste fram under intervjuet. For ham signaliserer lydkvaliteten at det er gammel musikk, men ikke nødvendigvis i den positive betydningen «ekte» og «autentisk», som moren vektlegger. Moren er inne på at sønnen reagerer på noe ved sangen til Prøysen. Spesielt interessant er det at hun også bemerker at det er noe med sangen som er annerledes enn slik hun husker det fra radioen. «Det er noe med stemmen,» 
forklarer hun, og uttrykker at hun ikke er helt fornøyd med cd-en, selv om det var den beste hun fant. Dette vitner om oppmerksom lytting, men samtidig mangel på begreper i hverdagsvokabularet som kan forklare og utdype det hun opplever, både overfor seg selv og meg som samtalepartner. Forskjellene mellom Prøysens visesang i hennes hukommelse og på cd-platen er likevel ikke så store at hun hemmes av det i særlig grad. Sønnen derimot kategoriserer musikken som «mamma sin» og «gammel» og sier at mannen på cd-en «synger rart». Han utdyper utsagnet med kroppsspråk som røper at han ikke liker det han hører.

Går en grundigere til verks er det flere elementer ved de innspilte visene som kan bidra til å belyse sønnens opplevelse. Om en sammenlikner sporene på denne cd-platen med andre av Prøysens radioinnspillinger, blir det tydelig musikalsk sett at innspillingene som er valgt er av hans tidligste radioinnspillinger. En har valgt å gå tilbake til det originale - det første - slik det opplyses på cdomslaget. Åpningssporet $\AA$, du gode sparegrisen min (1993c, spor 1) begynner rett på sangen uten innledende samtale, slik jeg har vært inne på, og Prøysens stemme bærer preg av den lyse, lette smidigheten, som også preget revyvisene fra 1940-tallet. Selv om Prøysen etter hvert ble kjent som en stemme fra distriktet, bar de tidligste radioinnspillingene av visene videre preg av datidens radiospråk, hvor dialekter fra distriktet ble erstattet av et utpreget bokmål med særegen vokaluttale. I en innspilling av den samme visen sendt 16. april 1969 for Barnetimen for de minste. Alf Prøysen forteller om «Teskjekjerringa reiser til Kanariøyene» (3:3) (Prøysen, 1969) er stemmeleiet lagt lavere og sangstemmen er nærmere Prøysens vennlige og jordnære fortellerstemme, med stort islett av brystklang. Her er det fortelleren Prøysen vi møter i barnevisene, i kontrast til revysangeren. Dialekten er tydelig til stede og han bruker ord som «fortælja», «fyst»og «deinn», som er typisk for hans Ringsakerdialekt. For en som har vokst opp med Ringsakerdialekt eller kjenner dialekten godt, vil nok denne innspillingen framstå som mer nær, varm og autentisk enn den som er tatt med på cd-platen.

Et annet eksempel på at musikalske elementer synes å skape distanse er innspillingen av Eplekartens sang som vi finner på cd-en (1993b, spor 6). Her sier Prøysen «efter», «gjennem»og «sner», og dette er langt fra Ringsakerdialekta. Sammenlikner vi med en innspilling av samme sang sendt i programmet Barnetimen. Alf Prøysen synger 8. oktober i 1949 (Prøysen, 1949) (hvor han også kommenterer at han har sunget sangen om Eplekarten et par år tidligere), er det nok likevel ikke dialekten som er den største utfordringen i innspillingen på cd-en. Den største forskjellen mellom de to innspillingene er toneleie og stemmebruk, og det kan høres ut som om dette delvis skyldes at innspillingen på cd-en er basert på et bånd som går i litt for høy hastighet. Toneleiet blir da høyere og stemmen høres presset ut, i tillegg til at det her er den lyse revystemmen vi møter. Videre bidrar det noe raske og rigide tempoet $\mathrm{i}$ seg selv til at resultatet framstår som mindre nært og varmt enn den senere innspillingene, fordi ordene, melodivendingene og andre musikalske virkemidler, som for eksempel ritardandi, ikke får tilstrekkelig tid til å utfolde seg og «synke inn» hos lytteren. I innspillingen fra 1949 er toneleiet som sagt langt lavere, og selv om han også her uttaler de nevnte ordene som «efter», «gjennem» og «sner» høres stemmeleiet mer komfortabelt ut, og formidlingen framstår som nært ham selv.

En siste forskjell jeg vil løfte fram her er akkompagnementet. I innspillingen av Eplekartens vise fra 1949 framføres visen med gitarakkompagnement som i sin enkelhet likevel i stor grad understøtter Prøysens sanglige formidling når det gjelder tempobevegelser og spenningskurver i fortelling og musikk. I innspillingen som er valgt på cd-en akkompagneres sangen av piano, og akkordene som legges gjør lite for å utdype den sanglige formidlingen. Alt i alt blir fortellingen om Eplekarten i denne versjonen distansert. Stemmebruk og akkompagnement er mindre egnet til å formidle innholdet med innlevelse, enn versjonen som er spilt inn noen år senere. 
Det musikalske uttrykket som er løftet fram på cd-en som helhet etterstreber en form for historisk autentisitet, i og med at en i stor grad har valgt Prøysens tidligste innspillinger av barnevisene. Dette er i tråd med cd-omslagets beskrivelse av at det dreier seg om originale versjoner av Prøysens barneviser. En kunne tenke seg at en hadde valgt annerledes, og mer i tråd med NRKs egne diskusjoner om hva som til enhver tid passer for barn. I NRKs arkiver finnes eksempler på vurderinger av eldre barneprogrammer, som ønskes sendt på nytt, hvor en kommer fram til at det er nødvendig å tilpasse materialet, slik at det passer til «våre ører i dag». ${ }^{5}$

\section{Oppsummering og diskusjon}

I denne teksten har jeg analysert en mor og en sønns erfaring med Prøysens barneviser ved å utdype dimensjonene morens barndomsminner, barnevisene i radioen og den aktuelle cd-platen. Jeg har gjort dette ved å anvende en kombinasjon av to ulike teoretiske tilnærminger. Gjennom det mer antropologisk orienterte perspektivet vektlegges hvordan musikken åpner for minner om tid og sted (DeNora, 2000; Ruud, 1997). Morens barndoms sted inneholder radioen som kulturell artefakt og opplevelsene knyttet til radioprogrammene i et livsverdensperspektiv (jf. Buckingham, 2008). Bolter og Grusins (1999) medieteori fokuserer på hvordan selve mediet og medieinnholdet remedieres i det nye mediet, i dette tilfellet i cd-spilleren og -platen. Kombinasjonen av disse teoretiske perspektivene utdyper hvordan radiomediet og bruken av det i faktiske sosiale sammenhenger «henger med» (jf. Bolter og Grusin, 1999) i bruken, men også i opplevelsen av cd-platen for moren.

Det er som om mediene moren stiller til rådighet formidler «for lite» for sønnen sammenliknet med det hun ønsker og forventer at han skal oppleve. Både cd-platen selv og moren vektlegger at cden etteraper radiomediet og radiomediets innhold. I tillegg forholder moren seg til barnevisene nærmest som om meningsinnholdet hun har tilskrevet dem er umiddelbart tilgjengelig for sønnen. Verken cd-en eller moren gir imidlertid barnet egentlig mulighet til å ta del i det som etterapes, samtidig som det etterapede settes opp som (uoppnålig) utgangspunkt og ideal for barnets opplevelse.

Dette kan altså beskrives som hypomediering, som utilstrekkelig mediering. Den er karakterisert av det motsatte av hypermedieringens overflod, nemlig knapphet, utilstrekkelighet og for lite å gripe fatt i for sønnen. Han blir dermed ikke berørt, slik moren håper.

\section{«Naervar»» - er det mulig å formidle en barndommens essens «rett-i-koppen»?}

Morens fortelling om egen opplevelse vitner om at immedialitetens og hypermedialitetens mål om å gjøre mediet usynlig oppnås. Når cd-platen settes på, overskrides den som medium for moren, og hun opplever at hun kommer nær erfaringen av barnevisene i radio i egen barndom. Både radiomediet og barnevisene overskrides imidlertid også, og hennes egne barndomsfølelser av trygghet og kjærlighet står igjen som noe hun kjenner det som at hun har direkte kontakt med.

$\AA$ kombinere de mer antropologiske perspektivene som omhandler musikkopplevelse, minnearbeid (jf. Ruud, 1997) og metaforen om musikk som en beholder (jf. DeNora, 2000) med Bolter og Grusins (1999) medieteori utløser i dette eksempelet et behov for å utvide rammen for hva som defineres som et medium. Tidligere i teksten ga jeg en mer allmenn forståelse av medier, altså medium som det «mellom» eller «i midten». En slik definisjon gir mulighet til å inkludere musikk, fortelling, hele radioprogrammer, tilstedeværende mennesker og så videre - kort sagt alle mer eller mindre konkrete faktorer som etter antropologisk teori forstås å utgjøre et «sted» (Casey, 1996), ikke bare radio og cd. I

\footnotetext{
${ }^{5}$ Sitert fra intern skriftlig beskjed uten avsender, sannsynligvis sendt til Else Ditlefsen. Hentet fra NRKs Dokumentarkiv.
} 
morens hukommelse er det som om radioen, barnevisene, fortellingene, foreldre, søsken, venner og Prøysen som nær og formidlende barnetimeonkel alle gestaltes som medier som medierer og remedierer til henne i hukommelsen det hun oppfatter som barndommens følelse av glede, trygghet, nærhet og ekthet - alt det som kanskje best kan beskrives som hennes barndoms emosjonelle landskap. For henne er dette en essens ved tilværelsen som hun søker å videreformidle til sønnen ved hjelp av barnevisene.

Men som vi har sett går ikke dette, fordi dette emosjonelle landskapet slik moren kjenner det ikke ligger lagret i barnevisene som sådan. Forstått ut fra hvordan morens musikkopplevelse kommer i stand, som en årelang prosess som strekker seg over flere livsfaser, er det som om hun hopper over flere ledd når hun forsøker å formidle opplevelsen til sønnen. Hun forsøker å gi ham en slags preprodusert «rett-i-koppen»-ballast, som hun synes å oppfatte at nærmest ligger ferdig i visene, klare til å røres ut i barnets beholder, for å trekke på DeNoras metafor. Men beskrevet med DeNora (2000) er det gjennom faktisk musikkbruk at mening konstitueres, og morens meningskonstitueringer er kun tilgjengelig som «nærvær» for henne selv.

\section{Redefinering}

Bolter og Grusin (1999) understreker behovet for redefinering når et medium eller et medieuttrykk gjenbrukes $i$ et nytt medium. En større åpning for redefinering av barnevisene $i$ formidlingen til sønnen ville kanskje kunne bidratt til å vekke sønnens interesse for dem. Muligens kunne moren kompensert for sin egen flermedierte og overskridende opplevelse (delvis muliggjort ved hjelp av hukommelsen), ved å tilby sønnen et mangfold av møter med Prøysens barneviser gjennom flere medier, for eksempel i andre cd-innspillinger med andre fortellere og utøvere, nyere bøker med Prøysens fortellinger og nyere sangbøker eller tv-innspillinger av eldre og nyere dato. At dette ville kunne bidra til en rikere opplevelse for sønnen kan støttes av Bolter og Grusins (1999) begrep om hypermediering. Men dette er ikke så aktuelt for henne, uttaler hun, fordi hun ønsker å formidle det som for henne er det ekte, og ikke nyere ting som hun oppfatter som inautentiske, både i innhold og uttrykk.

Jeg vil låne Bolter og Grusins redefineringsbegrep til å løfte fram at moren heller ikke gir rom for en redefinering av selve barnevisenes meningsinnhold i sønnens møte med dem. Mangel på mulighet for redefinering bidrar til at musikken får streif av noe dokumentarisk, som om det ikke er visene som spilles for ham, men morens barndom. Siden morens barndom ikke uten videre er mulig for ham å gripe, får musikken karakter av nettopp «bare» å være «noe fra morens barndom», og han beskriver som tidligere nevnt musikken som «gammel». Cd-platen framstår i dette perspektivet som en auditiv minnebok, hvor produsenten har «samplet» lyden av morens egen barndom, slik at hun kan spille av hvert spor på tilsvarende måte som om hun så på bildene i et fotoalbum. Det er dermed nærliggende å beskrive formidlingen fra sønnens perspektiv som om en annen barndom er «klippet inn» i hans egen, uten at han har referansene til å forstå den og ha glede av den. Ved å spille videre på DeNoras (2000) beholdermetafor, kan en beskrive det som om morens fortelling og forventning legger et lokk over Prøysens barneviser for sønnen, og hindrer ham i å fylle dem med mening.

\section{Trostende avslutning - Den forste lovetann}

Innledningsvis siterte jeg et par strofer fra Prøysens vise Den første løvetann: Det aller største mor vet om, er nemlig guttemann, som kommer hjem og har med seg sin første løvetann. Mens de andre barna fort og flinkt samler en blåveisblå bukett, plukker Lillebror i visen et blomstrende bustehode $i$ en sølepytt. Morens blåveisblå bukett av barneviser lar sønnen stå i det empiriske eksempelet som er 
analysert i denne artikkelen, selv om moren formidler buketten til sønnen med tilsvarende følelser av kjærlighet og ømhet som dem som beskrives i visen om løvetannen. Det største moren vet om, forstått som gleden over musikk og barndommens følelser av trygghet, er for henne tett koblet til buketten av barneviser. Derfor vil hun så gjerne at sønnen skal plukke de vakre, blåveisblå visene hun kjenner. Sønnen er derimot mer interessert i musikken vennene hører på, som er mer som bustehoder å regne etter morens vurdering. Men visens visdom beskriver morens valg når hun reforhandler sine egne musikalske kvalitetskriterier, og setter målet om felles opplevelser med sønnen høyest; som i visen om løvetannen blir det likevel stort for moren, beskriver hun senere i intervjuet, når hun gir rom for «sønnens musikk». Når de sammen opplever glede, nærhet og felleskap med disse sangene, er det for henne riktignok ikke det samme som det ville vært dersom de hadde hørt på hennes barndoms viser, uttrykker hun. Men hun ser at sønnen har glede av denne musikken, og hun lar seg rive med og gleder seg over det. Slik legges grunnlaget for at det for ham kan bli musikken han hører på både med vennene og moren som er beholderen han senere i livet kan åpne, og erfare at barndomsminner om nærhet, felleskap og trygghet strømmer ut og beriker hans liv også i voksen alder.

\section{Om forfatteren}

Ingeborg Lunde Vestad er førsteamanuensis i musikk ved Høgskolen i Hedmark, Norge. Hun har bakgrunn fra musikkvitenskap og -pedagogikk, og hennes forskningsinteresser omfatter musikk i barnekultur, herunder barns musikalske hverdagsliv og barnemusikk i mediene. Vestad har publisert i nordiske og internasjonale tidsskrifter, slik som Nordic Research in Music Education Yearbook, Music Education Research og Action, Criticism \& Theory for Music Education. Hun underviser ved høgskolens barnehagelærerutdanning, faglærerutdanning i musikk og masterutdanning i Kultur- og språkfagenes didaktikk.

\section{Litteratur}

Bergmo, Tonje (2013). Hysj, hysj, hysj! Nå blir det virkelig stille. Lokalisert på www.nrk.no/kultur/barnetimen-legges-ned-1.11398739

Buckingham, David (2008). Children and meda: A cultural studies approach. I K. Drotner \& K. Livingsonte (red.), International handbook of children, media and culture (s. 219-237). London: Sage.

Bolter, Jay David \& Grusin, Richard (1999). Remediation: Understanding new media. Cambridge: MIT Press.

Casey, Edward S. (1996). How to get from space to place in a fairly short stretch of time: Phenomenological prolegomena. I S. Feld \& K. H. Basso (Red.), Senses of place (s. 13-52). Santa Fe: School of American Press.

Dahl, Hans Fredrik (1999). Hallo-hallo! Kringkastingen i Norge 1920-1940. Oslo: Cappelen.

DeNora, Tia (2000). Music in everyday life. Cambridge: Cambridge University Press.

Ditlefsen, Else (u.å.). [Lydopptak.] [Upublisert intervju.]

Ditlefsen, Else (1995). Barnetimen for de minste: Litt forhistorie og historie. [Upublisert dokument, datert 18.01.1995.] Dokumentarkivet, NRK, Oslo.

Hammersley, M. \& Atkinson, P. (2007). Ethnography: Principles in practice (3. utg.). London: Routledge.

Kahn, Miriam (1996). Your place and mine: Sharing emotional landscapes in Wamira, Papua New Guinea. I S. Feld \& K. H. Basso (Red.), Senses of place (s. 167-196). Santa Fe: School of American Press.

Kongsrud, Helle Therese \& Kristiansen, Audun (2014). Fant forsvunnet Prøysen-opptak. Lokalisert på www.nrk.no/ho/fant-forsvunnet-proysen-opptak-1.12054565

Kvale, Steinar \& Brinkman, Svend (2009). Det kvalitative forskningsintervju (2. utg.). Oslo: Gyldendal akademisk. 
Programbladet (1947, 5. oktober). Oslo: NRK.

Prøysen, Alf (1949, 8. oktober). Eplekartens sang. I Barnetimen. Alf Prøysen synger (produsent ukjent). Oslo: Norsk Rikskringkasting. Tilgjengelig i Nasjonalbiblioteket.

Prøysen, Alf (1969, 16. april). Sparegrisen. I Barnetimen for de minste. Alf Prøysen forteller om «Teskjekjerringa reiser til Kanariøyene» (3:3) (produsent ukjent). Oslo: Norsk Rikskringkasting. Tilgjengelig i Nasjonalbiblioteket.

Prøysen, Alf (1993a). Original Prøysen 4: Hompetitten, 42 barneviser (1946-57 ). [CD]. [Oslo]: Kirkelig kulturverksted/NRK.

Prøysen, Alf (1993b). Eplekartens sang. [Innspilt av A. Prøysen]. På Original Prøysen 4: Hompetitten, 42 barneviser (1946-57). [CD]. [Oslo]: Kirkelig kulturverksted/NRK.

Prøysen, Alf (1993c). Å, du gode sparegrisen min. [Innspilt av A. Prøysen]. På Original Prøysen 4: Hompetitten, 42 barneviser (1946-57). [CD]. [Oslo]: Kirkelig kulturverksted/NRK.

Ruud, Even (1997). Musikk og identitet. Oslo: Universitetsforlaget.

Schröder, Amund (1958). Lasse og Nusse og Simsalabim. Manus til barnetimen for de minste sendt 28. april 1958.

Vestad, Ingeborg Lunde (2004). Barneplater - kultur eller bare kult?: En intervjuundersøkelse i familieperspektiv (Hovedoppgave). Oslo: Universitetet i Oslo, Institutt for musikkvitenskap.

Vestad, Ingeborg Lunde (2013). Barns bruk av fonogrammer: Om konstituering av musikalsk mening $i$ barnekulturelt perspektiv (Doktorgradsavhandling). Oslo: Universitetet i Oslo, Institutt for musikkvitenskap.

Wetlesen, Tone Schou (2000). A gi videre: Kultur og oppdragelse i familien. Bergen: Fagbokforlaget. 